\title{
Kerfs width analysis for wire cut electro discharge machining of SS 304L using design of experiments
}

\author{
Vishal Parashar, A. Rehman, J.L. Bhagoria, Y.M. Puri ${ }^{1}$ \\ Department of Mechanical Engineering, Maulana Azad National Institute of Technology, Bhopal, M.P., 462051, India \\ ${ }^{1}$ Department of Mechanical Engineering, Vishweshvariya, National Institute of Technology, Nagpur, Maharashtra, India \\ parashar17@rediffmail.com
}

\begin{abstract}
In this paper, statistical and regression analysis of kerf width using design of experiments is proposed for WEDM operations. Experimentation was planned as per Taguchi's L'32 $\left(2^{1} \times 4^{4}\right)$ mixed orthogonal array. Each experiment has been performed under different cutting conditions of gap voltage, pulse ON time, pulse OFF time, wire feed and dielectric flushing pressure. Stainless steel grade 304L was selected as a work material to conduct the experiments. From experimental results, the kerf width was determined for each machining performance criteria. Analysis of variance (ANOVA) technique was used to find out the variables affecting the kerf width. Assumptions of ANOVA were discussed and carefully examined using analysis of residuals. Variation of the kerf width with machining parameters was mathematically modeled by using the regression analysis method. Finally, the developed model was validated with a new set of experimental data and appeared to be satisfactory.
\end{abstract}

Keywords: Kerf width, Taguchi method, ANOVA, WEDM.

\section{Introduction}

Wire cut electro discharge machining (WEDM), a form of EDM, is a non-traditional machining method that is widely used to pattern tool steels for die manufacturing. WEDM uses electro-thermal mechanisms to cut electrically conductive material. The material is removed by a series of discrete discharges between the wire electrode and the work material in the presence of a dielectric fluid. Which creates a path for each discharge as the fluid becomes ionized in the gap. The region in which discharge occurs is heated to extremely high temperatures, so that the work surface is melted and removed. The flowing dielectric then flushes away the removed particles. The strength and hardness of the work materials are not significant factors in EDM. Only the melting point of the work material is an important property. Although WEDM machining is complex, the use of this machining process in industry has increased because of its capability in cutting complicated forms, especially created in hard materials (kanlyasiri \& Boonmung, 2007). Among the various non-conventional machining methods available, EDM is the most widely used and successfully applies one for the difficult to machine materials (George et al., 2004). WEDM has become the essential part of many manufacturing process industries, which need variety, precision and accuracy. Therefore, in order to improve the various performance characteristics in WEDM

Research article (OIndian Society for Education and Environment (iSee)

process, several researchers attempted previously. However, the full potential utilization of this machining process is not completely solved because of its complex and stochastic nature and the increased number of variables involved in the operation (Kuriakose et al., 2005; Manna \& Bhattacharyya, 2006; Ramakrishnan et al., 2006). The setting of machining parameters relies strongly on the experience of operators and machining parameter tables provided by machine tool builders. It is difficult to utilize the optimal functions of a machine owing to there being too many adjustable machining parameters (Mohammadi et al., 2008). The Taguchi's dynamic experiments are simple, systematic and efficient method to determine optimum or near optimum settings of machining parameters (Chang et al., 2006; Mahapatra et al., 2007; Mohammadi et al., 2008). The analysis of variance (ANOVA) is widely used to consider effects of factors on responses. In experimental investigations, ANOVA is often employed prior to other statistical analysis. Then regression analysis which establishes a

Fig 1. Details of kerf width (Mahapatra et al., 2007)

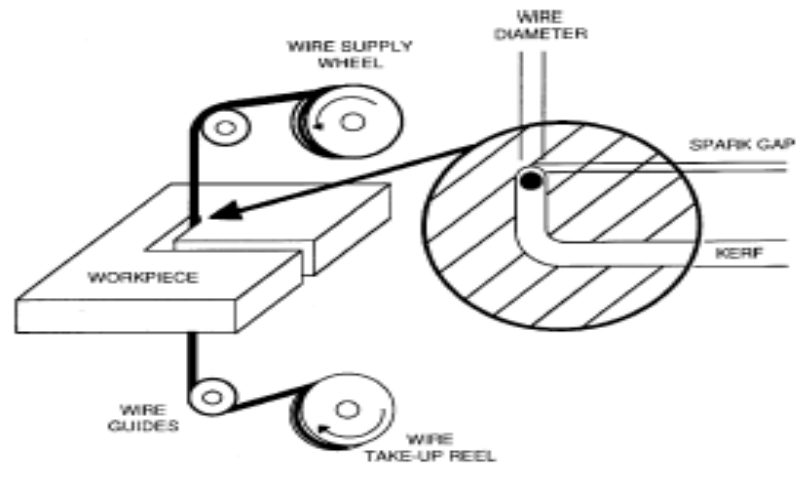

"Kerf width analysis" http://www.indjst.org relation

between independent variables and dependent variables is widely applied (Mohammadi et al., 2008). Kerf width is one of the important performance measures in WEDM. Kerf width is the measure of the amount of the material that is wasted during machining. It determines the dimensional accuracy of the finishing part. The detailed section of the Kerf width is shown in Fig. 1.

Vishal et al. Indian J.Sci.Technol. 


\section{Indian Journal of Science and Technology}

Vol. 3 No. 4 (Apr. 2010)

ISSN: 0974- 6846

The internal corner radius to be produced in WEDM operations are also limited by the Kerf width. The wire-workpiece gap usually ranges from 0.025 to $0.075 \mathrm{~mm}$ and is constantly maintained by a computer controlled positioning system. In WEDM operations, material removal rate (MRR) determines the economics of machining and rate of production. In setting the machining parameters, the main goal is the maximum MRR with the minimum Kerf width (kanlyasiri \& Boonmung, 2007).

The main purpose of this paper is to investigate effects of machining parameters on the kerf width of wire EDMed stainless steel grade $304 \mathrm{~L}$. From the basic principle and characteristic feature of the WEDM process for the machining of SS 304L, It has been observed that the machining parameters, such as gap voltage, pulse on-time, pulse off-time, wire feed and dielectric flushing pressure are the important controllable process parameters of the WEDM process, therefore, these machining parameters are used for the investigation. A proper design of experiments
Table 2. Selected machining parameters \& their levels

\begin{tabular}{|c|c|c|c|c|c|}
\hline \multirow{2}{*}{ Factor } & \multirow{2}{*}{ Unit } & \multicolumn{5}{|c|}{ Level } \\
\cline { 3 - 6 } & & 1 & 2 & 3 & 4 \\
\hline Gap voltage & Volts & 75 & 100 & - & - \\
\hline Pulse on time & Milliseconds & 0.12 & 0.16 & 0.15 & 0.08 \\
\hline Pulse off time & Milliseconds & 0.5 & 0.6 & 0.7 & 0.8 \\
\hline Wire feed & $\mathrm{RPM}$ & 700 & 800 & 900 & 1000 \\
\hline Flushing pressure & $\mathrm{Kgf} / \mathrm{cm}^{2}$ & 0.02 & 0.04 & 0.06 & 0.08 \\
\hline
\end{tabular}

Table 3. Analysis of variance for kerf width

\begin{tabular}{|l|c|c|c|c|c|c|}
\hline Source & DF & Seq SS & Adj SS & Adj MS & F & P \\
\hline Gap voltage & 1 & 225.78 & 225.78 & 225.78 & 2.87 & 0.107 \\
\hline Pulse on time & 3 & 2184.84 & 2184.84 & 728.28 & 9.27 & 0.001 \\
\hline Pulse off time & 3 & 144.34 & 144.34 & 48.11 & 0.61 & 0.616 \\
\hline Wire feed & 3 & 129.84 & 129.84 & 43.28 & 0.55 & 0.654 \\
\hline $\begin{array}{l}\text { Flushing } \\
\text { pressure }\end{array}$ & 3 & 1683.59 & 1683.59 & 561.20 & 7.14 & 0.002 \\
\hline Error & 18 & 1414.56 & 1414.56 & 78.59 & & \\
\hline Total & 31 & 5782.97 & & & & \\
\hline
\end{tabular}

Table 1. Chemical composition of Stainless Steel grade $304 L$.

\begin{tabular}{|l|l|}
\hline Chemical & $\%$ \\
\hline Chromium & $18.37 \%$ \\
\hline Nickel & $8.19 \%$ \\
\hline Manganese & $1.80 \%$ \\
\hline Copper & $0.58 \%$ \\
\hline Silicon & $0.54 \%$ \\
\hline Phosphorus & $0.039 \%$ \\
\hline Nitrogen & $0.037 \%$ \\
\hline Carbon & $0.021 \%$ \\
\hline Sulphur & $0.019 \%$ \\
\hline Fe & Balance \\
\hline
\end{tabular}

chosen for this experimentation. This is a water miscible metal working fluid.

Planning of experiments

In each experiment, a $10 \mathrm{~mm}$ width of work material was made to cut. The work material height was selected as $15.75 \mathrm{~mm}$, $25 \mathrm{~mm}$ and $29.5 \mathrm{~mm}$ respectively for the three replications of the experiment. The reason for selecting the variable thickness is to obtain the results for wide range. Ideally, the kerf width is determined by the Eq. 1. But due to the spark and deflection in electrode (Mingqi et al., 2005), the wire gap varies during the operation. Therefore actual value of kerf width was measured by using the JOEL scanning electron microscope (SEM). It was measured in microns. Kerf Width $=(2 \mathrm{Wg}+\mathrm{d})$

$$
\text { The }
$$

parameters machining vigorously affect the kerf width are identified based on experience, discussion made with the expert, survey of literature. Those are shown in Table 2.

\section{Data analysis}

To obtain a reliable database, each experiment was repeated three times and the mean values (DOE) is conducted to perform more accurate, less costly, and more efficient experiments. In the present research, an L'32 $\left(2^{1} \times 4^{4}\right)$ Taguchi standard orthogonal array was selected for the design of experiments (Phadke, 1989). Analysis of variance (ANOVA) was used as the analytical tool in studying effects of these machining variables. Assumptions of ANOVA were discussed and carefully examined using analysis of residuals. A mathematical model was developed using multiple regression method to predict kerf width.

Experimental details

Stainless steel grade $304 \mathrm{~L}$ was applied as work material for experimentation. The chemical composition of the selected work material is shown in Table 1.

Machine, electrode and dielectric

The experiments were carried out using CNC Ezeecut plus WEDM machine. Brass wire of $0.25 \mathrm{~mm}$ diameter was used as tool electrode in the experimental set up. This is a diffused wire of brass of type Duracut-E. Blasocut 4000 strong that is used as a dielectric fluid was were calculated. After all experiments are conducted, decisions must be made concerning which parameters affect the performance of a process and a mathematical model is developed to predict output amounts close to the actual amounts.

\section{Analysis of variance}

Analysis of variance (ANOVA) for kerf width was performed to study influences of the wire EDM machining variables. It is used to test the null hypothesis with regard to the data gained through experiments. Through null hypothesis it is assumed that there is no difference in treatment means $\left(\mathrm{H}_{0}: \mu_{1}=\mu_{2}=\ldots . .=\mu_{\mathrm{a}}\right)$. Table 3 is ANOVA table for kerf width. Before any inferences can be made based on ANOVA table, the assumptions used through ANOVA process have to be checked. The assumptions underlying the ANOVA tell the residuals are determined by evaluating the following Eq. (Matoorian et al., 2008).

$\mathrm{e}_{\mathrm{ij}}=\mathrm{y}_{\mathrm{ij}}-\hat{\mathrm{y}}_{\mathrm{ij}}$
Research article

COIndian Society for Education and Environment (iSee)
"Kerf width analysis" http://www.indjst.org
Vishal et al. Indian J.Sci.Technol. 
Where $e_{i j}$ is the residual, $y_{i j}$ is the corresponding observation of the experimental runs, $\hat{y}_{i j}$ is the fitted value.

A check of the normality assumption may be made by

error variance. So the larger value of $F$, the more important that factor is in influencing the process constructing the normal probability plot of the residuals. Fig. 2 depicts normal plot of residuals. This plot is used to test the normal distribution of errors. If the underlying error distribution is normal, this plot will resemble a straight line (Montgomery, 2001). This distribution shown in Fig. 2 presents that the error normality assumption is valid. Fig. 3 shows plotting of the residuals in time order of data collection. This method is helpful in checking independence assumption on the residuals. It is desired that the residual plot should contain no obvious patterns. Fig. 3 presents that independence assumption on the residuals was fulfilled for this experiment. Fig. 4 shows plot of residual versus fitted values. The structure less distribution of dots above and below the abscissa (fitted values) shows that the errors are independently distributed and the variance is constant (Montgomery, 2001). Therefore, it can be concluded that the assumption of constant variance of residuals was satisfied. Now those assumptions are proved not to be violated through this experimentation it can be relying on ANOVA results. Confidence level is chosen to be $95 \%$ in this study. So the $p$ values which are less than 0.05 indicate that null hypothesis should be rejected, and thus the effect of the respective factor is significant. The variance ratio denoted by $F$ in ANOVA tables, is the ratio of the mean square due to a factor and the error means square. In robust design $\mathrm{F}$ ratio can be used for qualitative understanding of the relative factor effects. A large value of $F$ means that the effect of that factor is large compared to the

Research article

CIndian Society for Education and Environment (iSee)

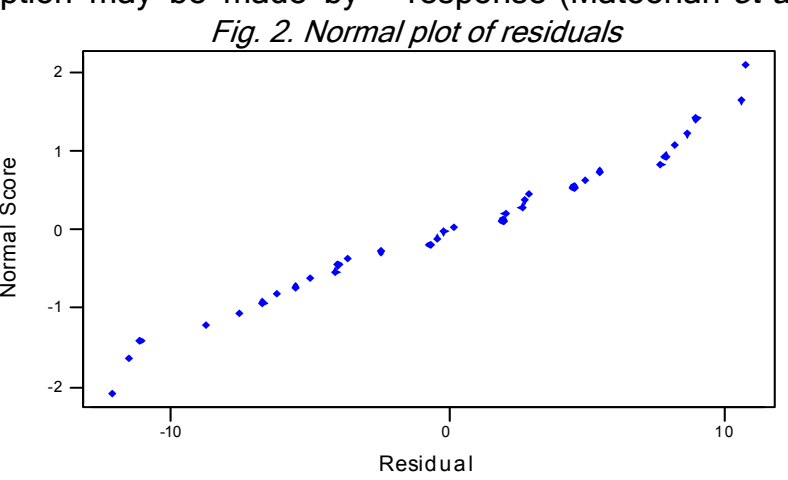

Fig. 3. Residuals in time order

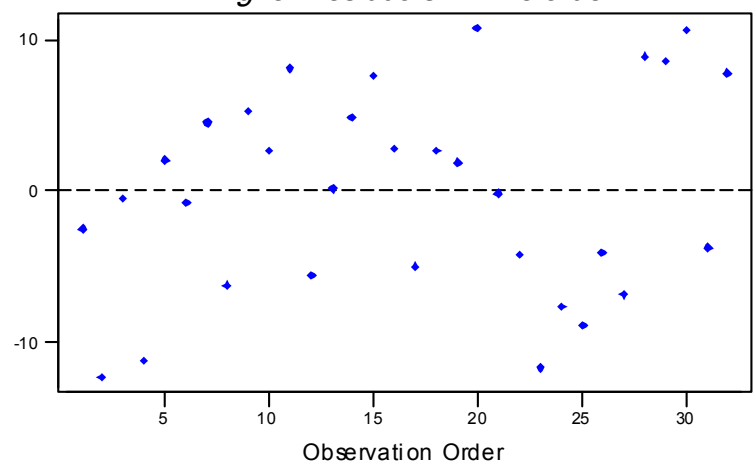

Fig. 4. Residuals vs. fitted values

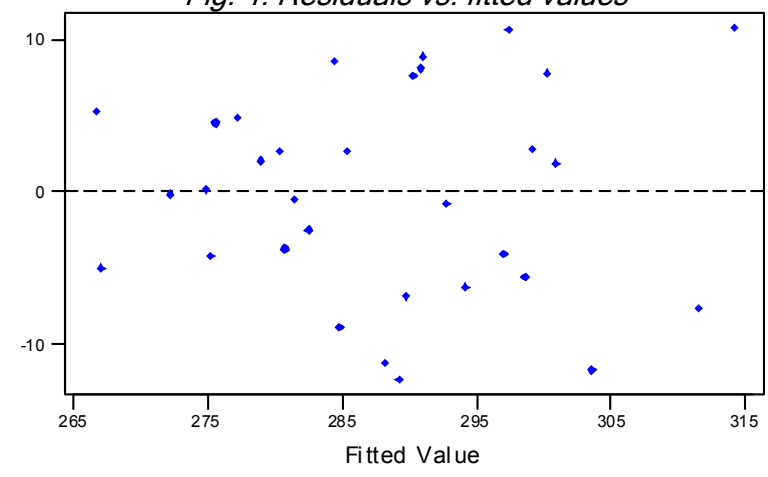

Table 4. Summarization of factor effects for kerf width.

\begin{tabular}{|c|c|c|}
\hline Factors & $\begin{array}{c}\text { Significance } \\
\text { level }\end{array}$ & $\begin{array}{c}\text { Proportionality } \\
\text { with regard to } \\
\text { surface } \\
\text { roughness }\end{array}$ \\
\hline $\begin{array}{c}\text { Gap } \\
\text { voltage }\end{array}$ & $\begin{array}{c}\text { Less } \\
\text { significance }\end{array}$ & Reciprocal \\
\hline $\begin{array}{c}\text { Pulse } \\
\text { on time }\end{array}$ & $\begin{array}{c}\text { Most } \\
\text { significance }\end{array}$ & Direct \\
\hline $\begin{array}{c}\text { Pulse } \\
\text { off time }\end{array}$ & $\begin{array}{c}\text { Less } \\
\text { significance }\end{array}$ & Reciprocal \\
\hline $\begin{array}{c}\text { Wire } \\
\text { feed }\end{array}$ & $\begin{array}{c}\text { Less } \\
\text { significance }\end{array}$ & Direct \\
\hline $\begin{array}{c}\text { Flushing } \\
\text { pressure }\end{array}$ & $\begin{array}{c}\text { Most } \\
\text { significance }\end{array}$ & Direct \\
\hline
\end{tabular}

"Kerf width analysis"

http://www.indjst.org Table 3, the most important factor was pulse on time with $9.27 \mathrm{~F}$ ratio and dielectric flushing pressure with $7.14 \mathrm{~F}$ ratio. The importance of other factors based on the $F$ ratio was respectively gap voltage, pulse off time and wire feed. Table 4 provides information about proportionality of influential factors with regard to ANOVA results.

Regression analysis

Regression analysis is performed to find out the relationship between factors and kerf width. In conducting regression analysis, it is assumed that factors and the response are linearly related to each other. A multiple regression technique was used to formulate the gap voltage, pulse on time, pulse off time, wire feed and dielectric flushing pressure to the kerf width. For the sake of accuracy all five factors were used to formulate the equation. In general, the units of process factors differ from each other. Even if some of the factors have the same units, not all of these factors will be tested over the same range. Since factors gap voltage, pulse on time, pulse off time and flushing pressure have different units and different ranges in the experimental data set, regression analysis should not be performed on the raw or natural factors themselves. Instead they must be normalized before performing a regression analysis. The normalized factors are called coded factors. In this study, coded factors of gap voltage, pulse on time, pulse off time, wire feed and dielectric flushing pressure are used as the independent factors in the regression analysis. A coded factor must be defined for each of the actual factor. Regression analysis is Indian J.Sci.Technol. 
Indian Journal of Science and Technology

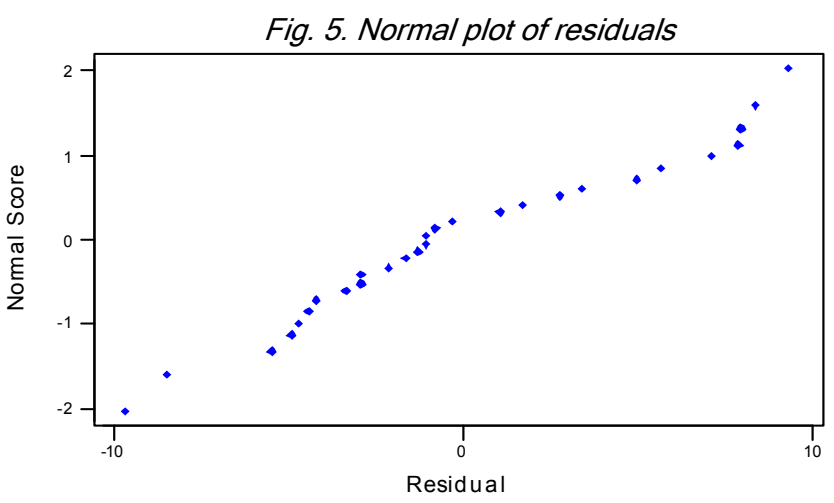

Fig. 6. Residuals in time order

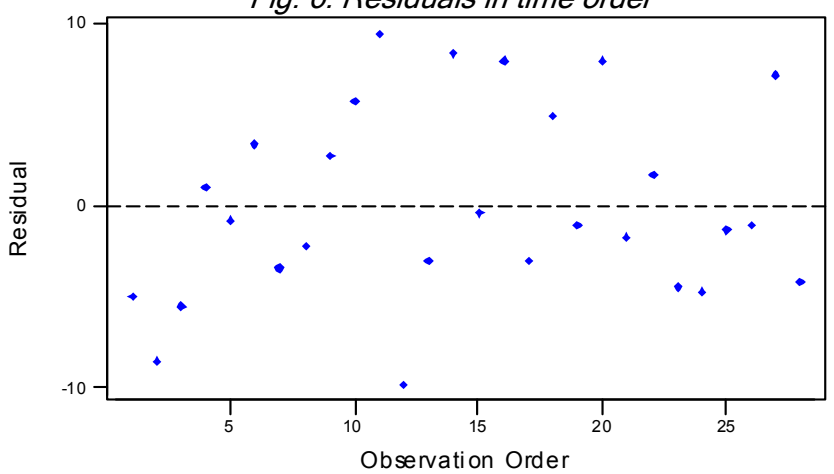

Fig. 7. Residuals vs. fitted values

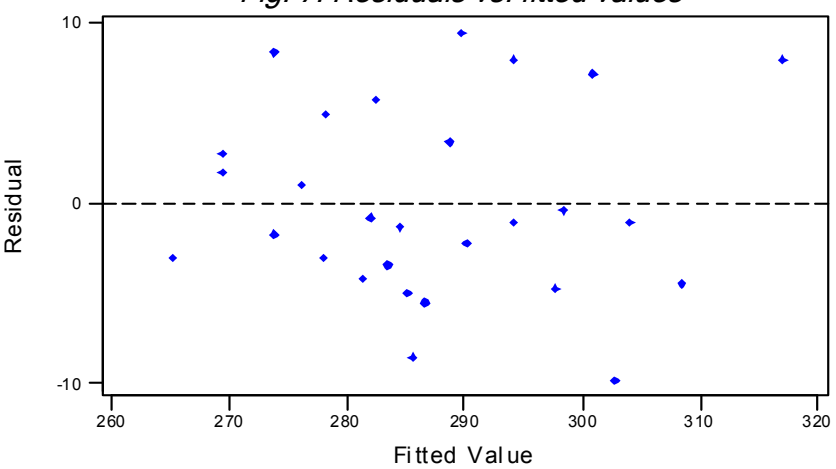

Table 5. ANOVA for regression analysis

then performed on the response variable as a function of coded factors. The general model to predict the kerf width over the experimental region can be expressed as Eq. 3.

$$
y=\beta_{0}+\beta_{1} x_{1}+\beta_{2} x_{2}+\beta_{3} x_{3}+\beta_{4} x_{4}+\beta_{5} x_{5}
$$

\begin{tabular}{|l|c|l|l|l|l|}
\hline Source & DF & SS & MS & F & P \\
\hline Regression & 5 & 4321.74 & 864.35 & 25.87 & 0.000 \\
$\begin{array}{l}\text { Residual } \\
\text { Error }\end{array}$ & 22 & 734.94 & 33.41 & & \\
\hline Total & 27 & 5056.68 & & & \\
\hline
\end{tabular}

Where, $y$ is the response and $x_{1}, x_{2}, x_{3}, x_{4}, x_{5}$ are the coded factors respectively. $\beta$ s are regression coefficients. The derived regression equation is as follows Kerf width $=296+10.1$ Gap voltage +8.03 Pulse on time - 0.71 Pulse off time

+ 5.52 wire feed - 11.8 Flushing pressure

From eqn. 4, the factors gap voltage, pulse on time and wire feed have an additive effect on the kerf width and pulse off time and flushing pressure have negative impact on kerf width. Analysis of the residuals of the model shown in Eq. 4 was performed to test assumptions of

\section{Conclusions}

Vol. 3 No. 4 (Apr. 2010)

ISSN: 0974- 6846

normality (fig. 5), independence (Fig. 6), and constant variance (Fig. 7) of residuals. The quantitative test methods mentioned earlier were employed again, and none of the assumptions was violated.

Analysis of variance was derived to examine the null hypothesis for the regression model that is presented in Table 5 . The results indicate that the estimated model by the regression procedure is significant at the a-level of confidence $(0.05)$. R-squared $\left(R^{2}\right)$ amount was calculated to check the goodness of the fit. $R^{2}$ is a measure of the amount of reduction in the variability of response obtained by using the regressor variables in the model. Because $\mathrm{R}^{2}$ always increases as we add terms to the model, some regression model builders prefer to use an adjusted $R^{2}$ statistic. In general, the $R^{2}$ adj statistic will not always increase as variables are added to the model. In fact, if unnecessary terms are added, the value of $R^{2}$ adj will often decrease. When $R^{2}$ and $R^{2}$ adj differ dramatically, there is a good chance that non significant terms have been included in the model (Montgomery, 2001). For this experiment the $R^{2}$ value indicates that the predictors explain $85.5 \%$ of the response variation. Adjusted $R^{2}$ for the number of predictors in the model was $82.2 \%$ both values shows that the data are fitted well.

The prediction model was then validated with another set of data. Table 6 shows verification of the tests results for kerf width. The predicted machining parameters performance is compared with the actual machining performance and a good agreement is observed between these performances. In Table 6 process factors are shown in terms of natural factors and their corresponding coded factors. In order to evaluate the accuracy of the prediction model, percentage error and average percentage error were used. Percentage of prediction errors is shown in the last column of Table 6 . The maximum prediction error was $3.4 \%$ and the average percentage error of this method validation was about $1.47 \%$. As a result, the prediction accuracy of the model appeared satisfactory. Fig. 8 shows the scanned electron microscope picture of one specimen.

This paper illustrates that the application of statistical analysis coupled with Taguchi design of experiments is simple, effective, and efficient in developing a robust and versatile EDM process. Results from this study were in agreement with findings in literature in which kerf width of EDMed workpiece depended on gap voltage, pulse on time, pulse off time, wire feed and flushing pressure $(3,6$, 8 \& 9). Although those research efforts performed on different materials other than SS304L, the outcomes were in accordance. The parameters affecting the kerf width were identified using ANOVA technique. Assumptions of ANOVA were tested using residual analysis. After careful
Research article

(OIndian Society for Education and Environment (iSee)
"Kerf width analysis"

http://www.indjst.org
Vishal et al. Indian J.Sci.Technol. 


\begin{tabular}{|c|c|c|c|c|c|c|c|c|c|c|c|c|}
\hline \multicolumn{4}{|c|}{ Natural factors } & \multicolumn{6}{|c|}{ Coded factors } & \multirow[b]{2}{*}{ 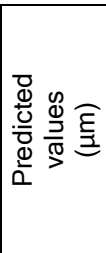 } & \multirow[b]{2}{*}{ 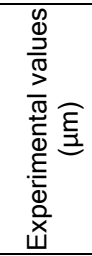 } & \multirow[b]{2}{*}{$\begin{array}{l}\frac{1}{0} \\
\frac{2}{0} \\
0 \\
0 \\
\frac{0}{0} \\
\stackrel{0}{0} \\
0 \\
\frac{0}{0} \\
0\end{array}$} \\
\hline 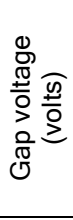 & 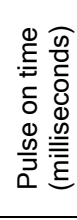 & 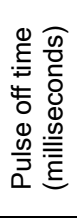 & 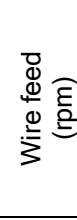 & 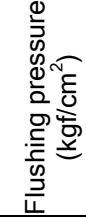 & $\mathrm{X}_{1}$ & $\mathrm{X}_{2}$ & $X_{3}$ & $\mathrm{X}_{4}$ & $X_{5}$ & & & \\
\hline 75 & 0.12 & 0.5 & 700 & 0.02 & -1 & -1 & -1 & -1 & -1 & 284 & 280 & 1.4 \\
\hline 75 & 0.16 & 0.6 & 800 & 0.04 & -1 & -0.5 & -0.5 & -0.5 & -0.5 & 285 & 277 & 2.8 \\
\hline 75 & 0.15 & 0.7 & 900 & 0.06 & -1 & 0.5 & 0.5 & 0.5 & 0.5 & 286 & 281 & 1.7 \\
\hline 75 & 0.08 & 0.8 & 1000 & 0.08 & -1 & 1 & 1 & 1 & 1 & 287 & 277 & 3.4 \\
\hline 75 & 0.12 & 0.5 & 800 & 0.04 & -1 & -1 & -1 & -0.5 & -0.5 & 281 & 281 & 0.0 \\
\hline 75 & 0.16 & 0.6 & 700 & 0.02 & -1 & -0.5 & -0.5 & -1 & -1 & 288 & 292 & 1.3 \\
\hline 75 & 0.15 & 0.7 & 1000 & 0.08 & -1 & 0.5 & 0.5 & 1 & 1 & 283 & 280 & 1.0 \\
\hline 75 & 0.08 & 0.8 & 900 & 0.06 & -1 & 1 & 1 & 0.5 & 0.5 & 290 & 288 & 0.6 \\
\hline 75 & 0.12 & 0.6 & 900 & 0.08 & -1 & -1 & -0.5 & 0.5 & 1 & 269 & 272 & 1.1 \\
\hline 75 & 0.16 & 0.5 & 1000 & 0.06 & -1 & -0.5 & -1 & 1 & 0.5 & 282 & 288 & 2.0 \\
\hline 75 & 0.15 & 0.8 & 700 & 0.04 & -1 & 0.5 & 1 & -1 & -0.5 & 289 & 299 & 3.3 \\
\hline 75 & 0.08 & 0.7 & 800 & 0.02 & -1 & 1 & 0.5 & -0.5 & -1 & 302 & 293 & 2.9 \\
\hline 75 & 0.12 & 0.6 & 1000 & 0.06 & -1 & -1 & -0.5 & 1 & 0.5 & 277 & 275 & 0.7 \\
\hline 75 & 0.16 & 0.5 & 900 & 0.08 & -1 & -0.5 & -1 & 0.5 & 1 & 273 & 282 & 3.1 \\
\hline 75 & 0.15 & 0.8 & 800 & 0.02 & -1 & 0.5 & 1 & -0.5 & -1 & 298 & 298 & 0.0 \\
\hline 75 & 0.08 & 0.7 & 700 & 0.04 & -1 & 1 & 0.5 & -1 & -0.5 & 294 & 302 & 2.6 \\
\hline 100 & 0.12 & 0.8 & 700 & 0.08 & -0.5 & -1 & 1 & -1 & 1 & 264 & 262 & 0.7 \\
\hline 100 & 0.16 & 0.7 & 800 & 0.06 & -0.5 & -0.5 & 0.5 & -0.5 & 0.5 & 277 & 283 & 2.1 \\
\hline 100 & 0.15 & 0.6 & 900 & 0.04 & -0.5 & 0.5 & -0.5 & 0.5 & -0.5 & 304 & 303 & 0.3 \\
\hline 100 & 0.08 & 0.5 & 1000 & 0.02 & -0.5 & 1 & -1 & 1 & -1 & 317 & 325 & 2.4 \\
\hline 100 & 0.12 & 0.8 & 800 & 0.06 & -0.5 & -1 & 1 & -0.5 & 0.5 & 273 & 272 & 0.3 \\
\hline 100 & 0.16 & 0.7 & 700 & 0.08 & -0.5 & -0.5 & 0.5 & -1 & 1 & 269 & 271 & 0.7 \\
\hline 100 & 0.08 & 0.5 & 900 & 0.04 & -0.5 & 1 & -1 & 0.5 & -0.5 & 308 & 304 & 1.2 \\
\hline 100 & 0.16 & 0.8 & 1000 & 0.04 & -0.5 & -0.5 & 1 & 1 & -0.5 & 297 & 293 & 1.3 \\
\hline 100 & 0.15 & 0.5 & 700 & 0.06 & -0.5 & 0.5 & -1 & -1 & 0.5 & 284 & 283 & 0.3 \\
\hline 100 & 0.12 & 0.7 & 1000 & 0.04 & -0.5 & -1 & 0.5 & 1 & -0.5 & 294 & 293 & 0.3 \\
\hline 100 & 0.16 & 0.8 & 900 & 0.02 & -0.5 & -0.5 & 1 & 0.5 & -1 & 300 & 308 & 2.5 \\
\hline 100 & 0.15 & 0.5 & 800 & 0.08 & -0.5 & 0.5 & -1 & -0.5 & 1 & 281 & 277 & 1.4 \\
\hline
\end{tabular}

3. Kanlyasiri $\mathrm{K}$ and Boonmung $\mathrm{S}$ (2007) An investigation on effects of wire-EDM machining parameters on surface roughness of newly developed DC53 diesteel. J. Mater. Proc. Technol.187, 26-29.

4. Kuriakose $S$ and Shunmugam MS (2005) Multi-objective optimization of wire-electro discharge machining process by non-dominated sorting genetic algorithm. J. Mater. Process. Technol. 170, 133141.

5. Mahapatra SS and Patnaik A (2007) Optimization of wire electrical discharge machining (WEDM) process parameters using Taguchi method. Int. J. Adv. Manuf. Technol. 34, 911925.

6. Manna A and Bhattacharyya B (2006) Taguchi and Gauss elimination method: A dual response approach for parametric optimization of CNC wire cut EDM of PRAISICMMC. Int J. Adv. Manuf. Technol. 28, 67-75.

7. Matoorian $P$, Sulaiman $S$ and Ahmad MMHM (2008) An experimental study for optimization of electrical

testing, none of the assumptions was violated. Results showed that, pulse on time and dielectric flushing pressure are the most significant factors, while gap voltage, pulse off time and wire feed are the less significant factor to the kerf width of wire EDMed SS304L. Finally a mathematical model was developed using multiple regression method to formulate the gap voltage, pulse on time, pulse off time, wire feed and dielectric flushing pressure to the kerf width. The developed model showed high prediction accuracy within the experimental region. The maximum prediction error of the model was less than $4 \%$ and the average percentage error of prediction was less than $2 \%$.

\section{References}

1. Chang TC, Tsai FC and $\mathrm{Ke} \mathrm{JH}$ (2006) Data mining and Taguchi method combination applied to the selection of discharge factors and the best interactive factor combination under multiple quality properties. Int. J. Adv. Manuf. Technol. 31, 164-174.

2. George PM, Raghunath BK, Manocha LM, Ashish MW (2004) EDM machining of carbon-carbon composite-a Taguchi approach. J. Mat. Proc. Technol. 145, 66-71.

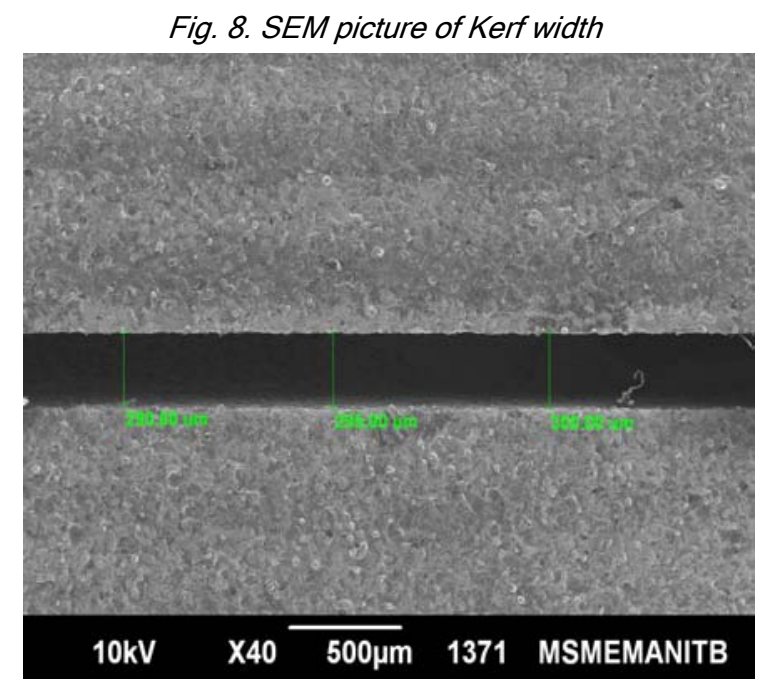
discharge turning (EDT) process. J. Mat. Proc. Technol. 204, 350-356.

8. Mingqi L, Minghui L and Guangyao X (2005) Study on the variations of form and position of the wire electrode in WEDM-HS. Int. J. Adv. Manuf. Technol. 25, 929-934.

9. Mohammadi A, Tehrani AF, Emanian A and Karimi D (2008) Statistical analysis of wire electrical discharge turning on material removal rate. J. Mat. Proc. Technol. 205, 283-289.

10. Mohammadi A, Tehrani AF, Emanian E and Karimi D (2008) A new approach to surface roughness and roundness improvement in wire electrical discharge turning based on statistical analyses. Int. J. Adv. Manuf. Technol. 39, 64-73.

11. Montgomery CD (2001) Design and analysis of experiments, John Wiley \& Sons.

12. Phadke MS (1989) Quality engineering using robust design, Prentice-hall, Englewood cliffs, NJ.

13. Ramakrishnan $R$ and Karunamoorthy L (2006) Multi response optimization of wire EDM operations using robust design of experiments. Int. J. Adv. Manuf. Technol. 29,105112. 